\title{
Measuring gender equality in education: Lessons from 43 countries
}

\author{
Stephanie Psaki \\ Population Council \\ Katharine McCarthy \\ Population Council \\ Barbara Mensch \\ Population Council
}

Follow this and additional works at: https://knowledgecommons.popcouncil.org/departments_sbsr-pgy

Part of the Demography, Population, and Ecology Commons, Family, Life Course, and Society Commons, Gender Equity in Education Commons, and the International Public Health Commons How does access to this work benefit you? Let us know!

\section{Recommended Citation}

Psaki, Stephanie, Katharine McCarthy, and Barbara Mensch. 2017. "Measuring gender equality in education: Lessons from 43 countries," GIRL Center Research Brief no. 2. New York: Population Council. Version of record: https://knowledgecommons.popcouncil.org/departments_sbsr-pgy/485/ 
GIRL Center Research Brief

No. 2 October 2017

MEASURING GENDER EQUALITY IN EDUCATION: LESSONS FROM 43 COUNTRIES

STEPHANIE PSAKI, KATHARINE MCCARTHY, AND BARBARA S. MENSCH

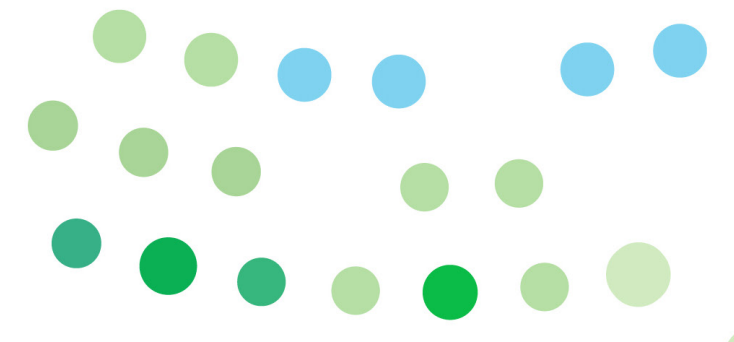


The Girl Innovation, Research, and Learning (GIRL)

Center generates, synthesizes, and translates evidence to transform the lives of adolescent girls.

popcouncil.org/girlcenter

GIRL Center Research Briefs present new knowledge on issues of current and critical importance and recommend future directions for research, policies, and programs.

Research reported in this brief was supported by a grant from Echidna Giving. The content is solely the responsibility of the authors and does not necessarily represent the official views of the funding institution.

Suggested citation: Psaki, Stephanie, Katharine McCarthy, and Barbara S. Mensch. 2017. "Measuring Gender Equality in Education: Lessons from 43 Countries," GIRL Center Research Brief No. 2. New York: Population Council.

This brief summarizes research forthcoming in a peer-reviewed journal: Psaki, Stephanie R., Katharine McCarthy, and Barbara S. Mensch. 2018. "Measuring gender equality in education: Lessons from 43 countries," Population and Development Review 44(1): Forthcoming. 
Through the 2015 Sustainable Development Goals, governments committed to achieving universal secondary school completion, including eliminating gender disparities, by 2030. Yet, by 2013 , only 14 percent of children in low-income countries had completed secondary school. And in many countries, even those who attend school fail to gain basic literacy and numeracy skills.

Using data on trends over 10 years in 43 countries, we go beyond simple measures of gender parity to investigate progress in achieving gender equality in education over the last few decades, and to identify opportunities to accelerate progress by 2030.

\section{KEY FINDINGS:}

1. Progress in girls' education has stagnated in many countries.

2. Despite gender parity in enrollment globally, in many countries female disadvantages persist.

3. Once enrolled in school, girls tend to complete as many grades as boys.

4. Gender parity in attainment may mask other important deficiencies in education.

5. Gender parity in attainment does not necessarily translate into gender parity in learning. 


\section{BACKGROUND}

Over the past few decades, policy and programmatic investments have brought significant improvements in gender equality in education around the world. Recent studies have shown that, on average, gender parity has been achieved globally in primary and secondary school enrollment (UNESCO 2016a), and, in some regions, while girls may not be as likely as boys to enter school, they progress as far as boys once they enroll (Grant and Behrman 2010).

In the face of these important successes, one might reasonably ask why continued investments in girls' education are necessary. The answer is that the progress we have seen masks variations in school enrollment and grade attainment within countries and regions, and widely used measures of success conceal important challenges. Moreover, these measures do not capture how gender gaps may be evolving, or other areas of potential gender inequality, such as learning outcomes and post-schooling opportunities (Lloyd 2009; Grant and Behrman 2010; UNESCO 2016a).

As policymakers, practitioners, and philanthropists consider the best ways to improve education for girls around the world, key questions remain:

- Where has gender parity in school enrollment not yet been achieved?

- How do patterns of school progression differ for girls and boys?

- Is gender parity in attainment likely to translate into parity in learning?

- Does parity in attainment mean that gender equality in education has been achieved? 


\section{METHODOLOGY}

Using Demographic and Health Survey (DHS) data collected at two time points in 43 low- and middle-income countries, we investigated progress in both improving primary school enrollment and attainment for girls and eliminating gender disparities. We consider a difference of more than five percentage points between girls and boys -in either direction - to be a gender gap. To assess progress, we compared the most recent key education indicators with those from a survey done 10 years earlier in each country. The earlier surveys (Time 1 ) were conducted between 1997 and 2007; the later surveys (Time 2) were carried out between 2008 and 2014. We include all countries where DHS data were collected since 2007.

Using these data, we first explored levels and trends in school enrollment and attainment for girls ages 15-19 in each of the 43 countries. Second, we investigated progress in closing gender gaps in each setting. Third, we combined this information to determine which countries have made progress on one or both of these dimensions. Last, we assessed whether efforts to eliminate gender gaps in school enrollment and attainment are likely to translate into gender parity in learning, and gender equality in education more broadly. More detail on the study methodology is provided in the peer-reviewed paper (Psaki, McCarthy, and Mensch, forthcoming).

\section{GLOBAL POLICY GOALS AND CHALLENGES}

Through the 2015 Sustainable Development Goals (SDGs), governments established a range of targets to meet by 2030 , including the following commitments on, and related to, education:

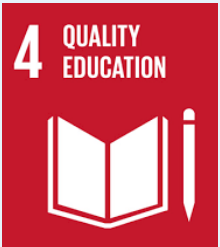

Goal 4 aims to "ensure inclusive and quality education for all and promote lifelong learning," including calling for universal completion of upper secondary education and the elimination of gender disparities in education.

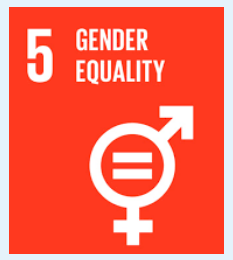

Goal 5 calls on countries to "achieve gender equality and empower all women and girls," including in economic, political, and public life.

Yet, by $\mathbf{2 0 1 3}$, only 70 percent of children in low-income countries had completed primary school, and only 14 percent had completed secondary school (UNESCO 2016b). UNESCO (2016a) acknowledged that, "if past trends continue, not even the [previous] goal of universal primary completion...is likely to be achieved by 2030. The target of universal secondary completion is clearly beyond reach (page 24)." Furthermore, assessments of basic literacy and numeracy skills in poor settings reveal that a considerable proportion of children, 50 percent or more in some countries, who have attended six years of primary school do not meet minimum standards of literacy (CGD 2013). Clearly, governments face a daunting task, with limited resources, in bridging the gaps between current levels of enrollment and attainment and aspirations laid out in global policy frameworks. 


\section{KEY FINDING 1}

\section{PROGRESS IN GIRLS' EDUCATION HAS STAGNATED IN MANY COUNTRIES.}

Global policies are designed based on an expectation that, with sufficient investments, countries will pass through a girls' education transition, advancing from low school enrollment levels with large female disadvantages, to high enrollment with gender parity. However, few countries made progress on both fronts.

Of the 43 countries included, between Time 1 and Time 2:

- Only three countries made substantial progress in both female attainment and gender parity;

- Five countries improved girls' attainment, but failed to eliminate gender gaps;

- Twelve countries narrowed gender gaps without substantially improving girls' attainment; and

- Fourteen countries did not make notable progress in either closing gender gaps or increasing attainment for girls, or new gender gaps emerged.

Only three countries (shown in light blue) made substantial progress in both female attainment and gender parity between Time 1 (1997-2007) and Time 2 (2008-2014)

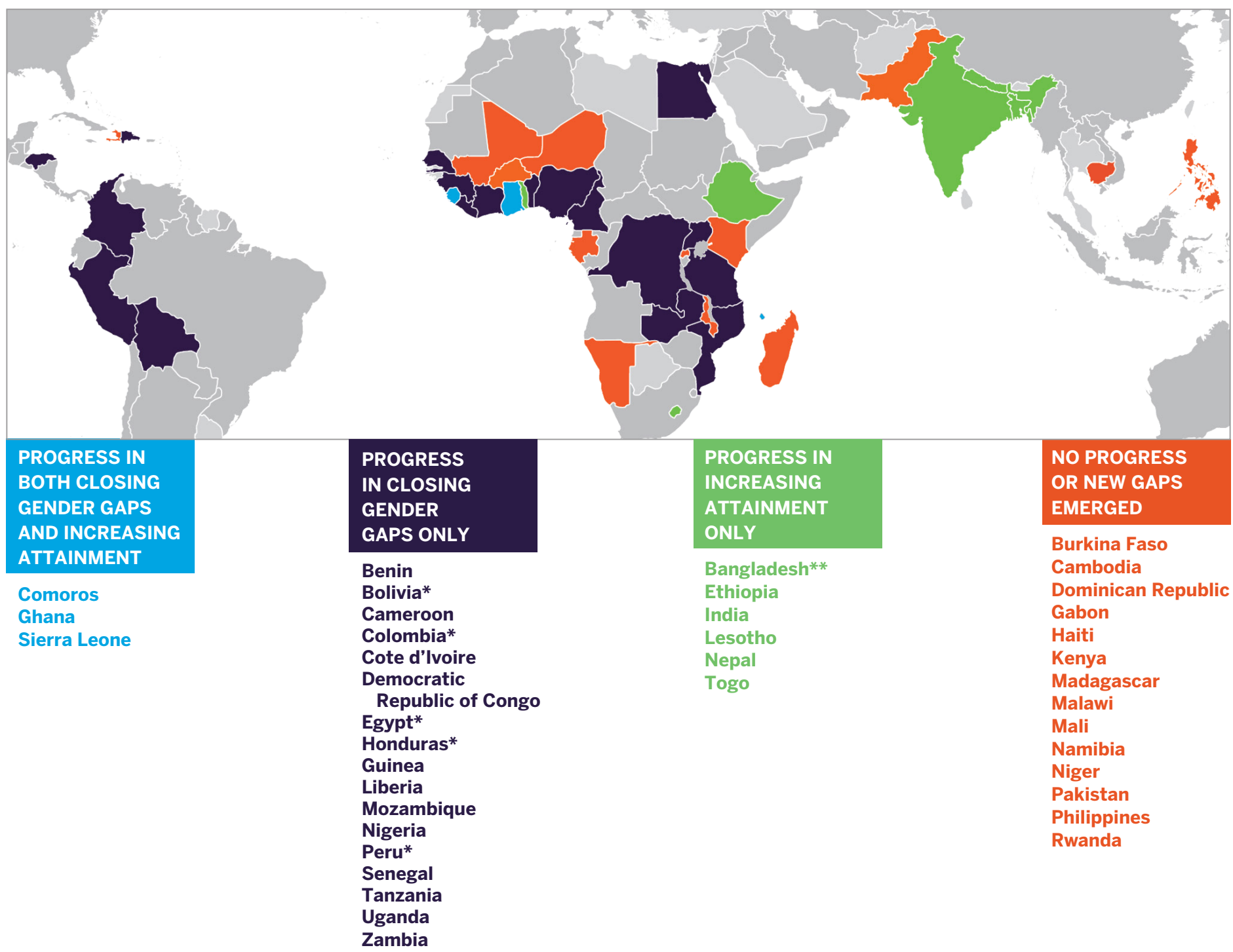

Note: In three countries (Jordan, Indonesia, Zimbabwe), both gender parity and high attainment had been achieved by Time 1.

* Signifies countries where levels of grade attainment were already high at Time 1.

** Signifies countries where gender parity had already been achieved at Time 1 . 


\section{DESPITE GENDER PARITY IN ENROLLMENT GLOBALLY, IN MANY COUNTRIES FEMALE DISADVANTAGES PERSIST.}

Despite UNESCO's declaration that gender parity had been achieved globally in primary education by 2014 (UNESCO 2016a), in 12 of the 43 countries in our study fewer girls than boys were enrolled in primary school at Time 2 (2008 to 2014).

Countries with female disadvantages in primary school enrollment at Time 2 were concentrated in West Africa and South Asia. Disparities at school entry are an important indicator of gender-related barriers to education, which may well persist after girls enter school in these countries. Note that there were no male disadvantages in enrollment at Time 2.

Countries where female disadvantages* in school enrollment persist are concentrated in West Africa and South Asia

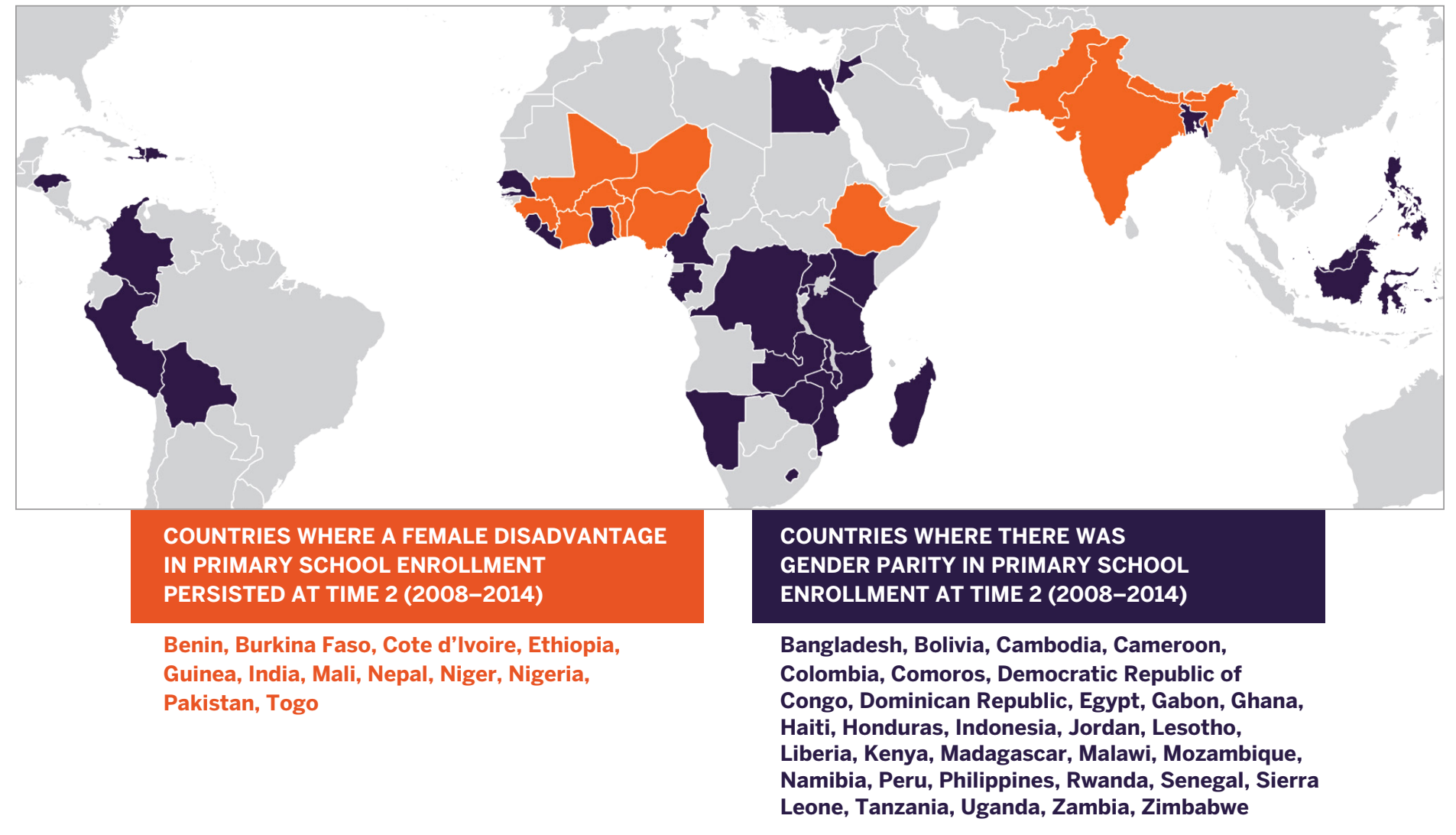

* "Disadvantage" is a difference of more than five percentage points. 


\section{KEY FINDING 3}

\section{ONCE ENROLLED IN SCHOOL, GIRLS TEND TO COMPLETE AS MANY GRADES AS BOYS.}

Many policymakers and practitioners interpret gender gaps in primary school completion as evidence that adolescent girls drop out of school more than adolescent boys. However, our data show a more nuanced pattern.

At Time 2, fewer girls than boys completed primary school in 12 countries. In 9 of those countries, the gap in attainment was completely due to gaps in school enrollment. That is, although fewer girls than boys enrolled in school, once enrolled, girls were just as likely to finish primary school as boys. In the other three countries, girls were less likely to enroll in primary school than boys, and they were also more likely than boys to drop out of primary school.

In many countries, gender gaps in attainment are due completely to gaps in school enrollment, not dropout

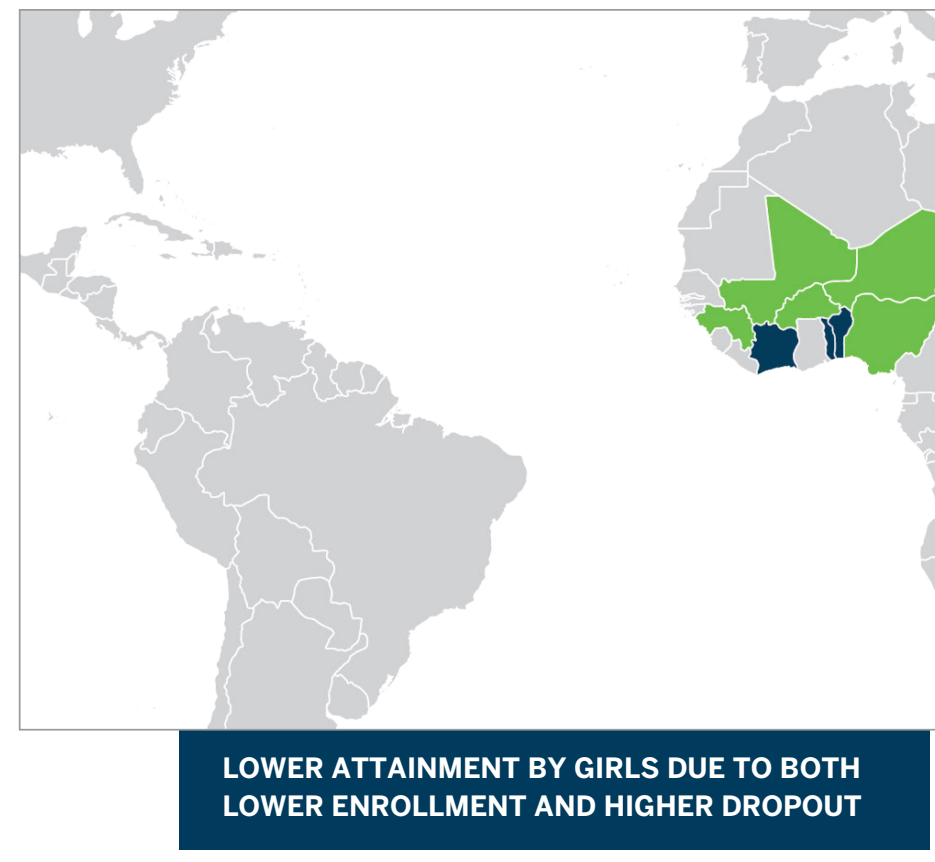

Benin, Cote d'Ivoire, Togo

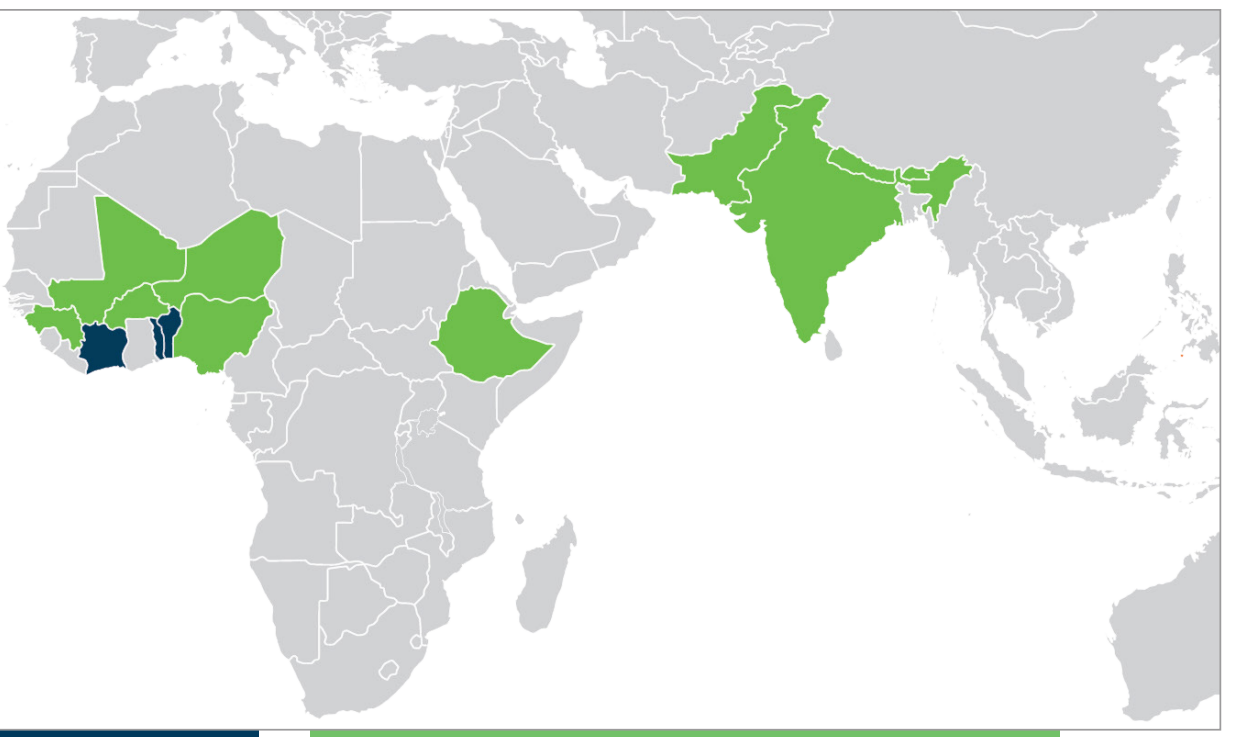

LOWER ATTAINMENT BY GIRLS DUE COMPLETELY TO LOWER ENROLLMENT

Burkina Faso, Ethiopia, Guinea, India, Mali, Nepal, Niger, Nigeria, Pakistan

\section{WHAT ABOUT BOYS?}

In several countries where most young people enter and complete primary school, male disadvantages in attainment have begun to emerge. Some observers have compared this to female disadvantages in schooling, but the settings where male and female disadvantages occur are very different.

Female disadvantages persist in countries with weak education systems, where both girls and boys are least likely to enter and complete primary school. Male disadvantages emerge in countries where both girls and boys are most likely to enter and complete primary school. Investing in strengthening weak education systems, where girls tend to be at a relative disadvantage, will benefit both boys and girls. 


\section{KEY FINDING 4}

\section{GENDER PARITY IN ATTAINMENT MAY MASK OTHER IMPORTANT DEFICIENCIES IN EDUCATION.}

When tracking progress in girls' education, it is important to distinguish between countries that have achieved gender parity at low versus high levels of educational attainment.

The figure below shows enrollment and attainment patterns in Malawi and Indonesia at Time 2. Although gender parity exists in both countries, both girls and boys in Malawi face serious barriers to education, whereas in Indonesia young people are much more likely to receive a primary education.

In settings with low enrollment and attainment, even when gender parity exists, there are likely shared barriers to school, such as poverty, as well as gender-specific barriers, such as unplanned pregnancy for girls and pressure to work for boys. As enrollment and attainment increase in settings like Malawi, it is possible that gender gaps will emerge.

School enrollment and attainment, 15-19-year-olds in Malawi and Indonesia, Time 2

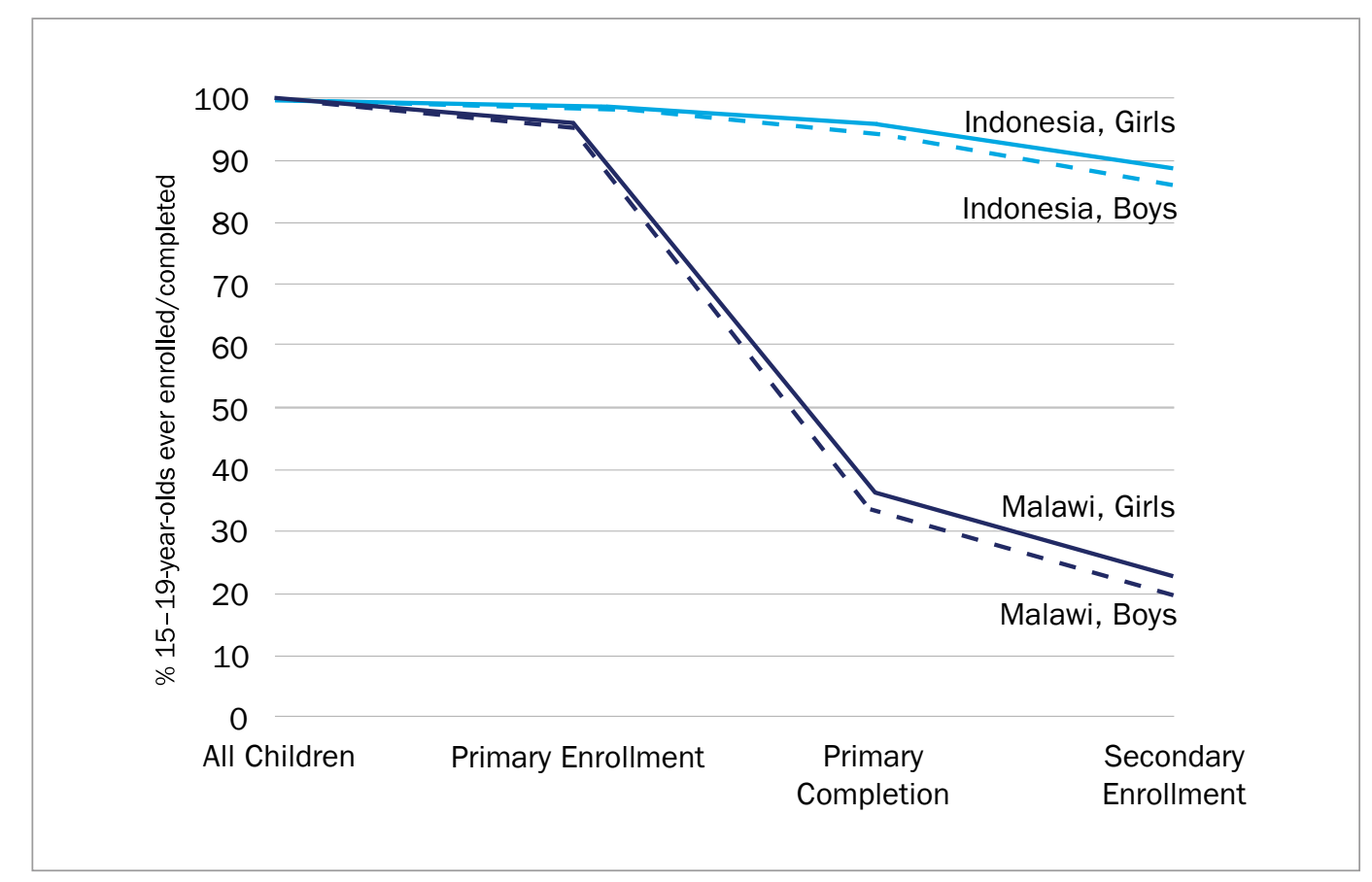




\section{KEY FINDING 5}

\section{GENDER PARITY IN ATTAINMENT DOES NOT NECESSARILY TRANSLATE INTO GENDER PARITY IN LEARNING.}

It may seem reasonable to assume that all 15-19-year-olds who completed primary school, regardless of sex, should have basic literacy skills. The figure below shows that this is not the case. At Time 2, among those who completed primary and did not continue in school, fewer than half of females in eight countries, and fewer than half of males in four countries, had basic literacy skills. And in nine of the countries shown, boys were more likely than girls to have basic literacy skills, despite completing the same level of education.

Percent 15-19-year-olds able to read a simple sentence, among those who completed primary school, Time 2 (2008-2014)

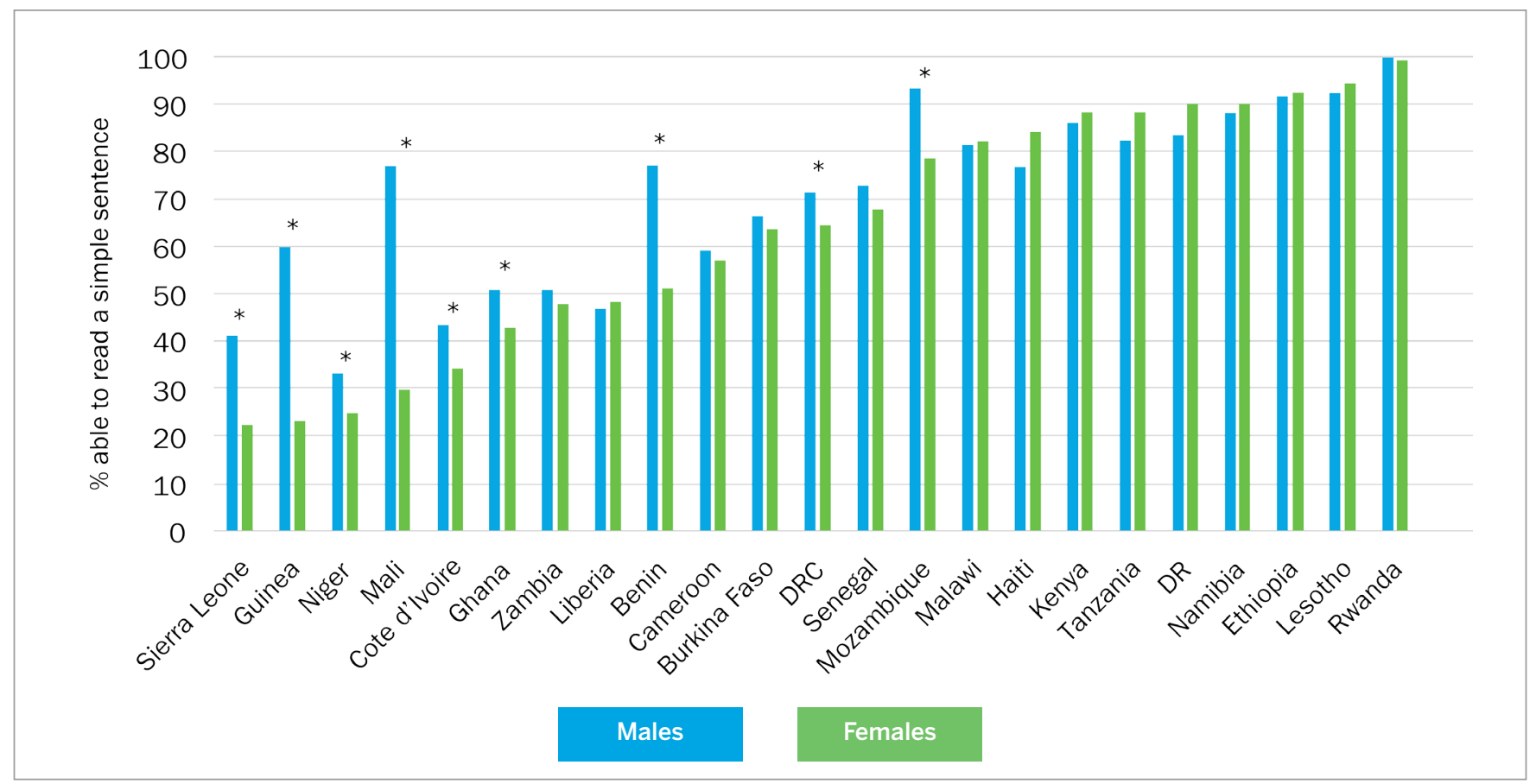

Note: Asterisk denotes a difference of five percentage points or more. 


\section{CONCLUSIONS}

The period from 1997 to 2014 saw considerable progress in closing gender gaps in school enrollment and attainment in many, but not all, low- and middleincome countries. However, claims that gender parity in primary education now exists are premature, especially in the poorest countries. Even where parity has been achieved, attainment levels are still low for both girls and boys in many countries, indicating that new gender gaps, or gender-related challenges, may emerge as attainment increases.

Moreover, the extremely low levels of secondary school enrollment-and even more so completion-demonstrate that the SDG target of universal secondary school completion is likely more aspirational than realistic without dramatic increases in investments in education in these settings. Improvements in the overall quality of education systems have proven even more elusive than improvements in attainment and gender parity, to the detriment of both boys and girls. 
1 Measures of progress in achieving gender equality in education must be broader.

Data on gender gaps in attainment should be combined with information on each country's stage in educational development; the levels of schooling at which gaps emerge and grow; gender-related barriers to school enrollment, progression, and learning; and gender differences in the return on investments in schooling. Choices about how progress is measured affect our ability to both understand challenges to achieving gender equality, and to design the most effective policies and interventions to address those challenges.

2 Continued investments are needed to get all girls into primary school.

Despite global progress in increasing enrollment and closing gender gaps, in many countries fewer girls than boys enroll in primary school. This disparity at school entry translates into gender gaps in primary school progression and completion. The global policy community should continue investments in closing these remaining gaps, while emphasizing the ultimate goal of secondary school completion for all. The progress made in a number of countries over the last two decades is encouraging, and suggests that the goal of truly global gender parity in enrollment and attainment-meaning for all young people in every country-is potentially achievable.

3 Girls' education policies should be designed based on when-and why-gaps emerge.

To help design effective policies, data on gender gaps in educational attainment must be combined with data on parity in primary school enrollment, the timing of dropout, and the reasons that girls leave school. Resources should be focused on the places and schooling levels where female disadvantages emerge or grow, recognizing that these gaps vary between countries and over time, and that gender gaps may emerge as enrollment increases in some countries.

0 Investments in girls' education must be designed to address gender parity and higher attainment in parallel.

Our results show that many countries made progress in closing gender gaps without increasing attainment for girls. Achieving gender parity, without substantial improvements in enrollment and attainment, will mean that many students-girls and boys alike-will go without the education they deserve. Girls are at a disadvantage in settings where school systems are weakest, so effective girls' education programs will need to not only address genderrelated barriers to schooling, but also the shared barriers to education affecting both girls and boys. Therefore, the most effective girls' education policies and programs are also likely to benefit boys.

\section{Policies and programs must continue to invest in improving school quality.}

Our findings show that gender parity in educational attainment is unlikely to translate into parity in learning given current levels of school quality. Further, many young people-both girls and boys-leave school without basic academic skills. And recent evidence from Malawi warns that young people, especially girls, may not retain academic skills, like literacy and numeracy, into adulthood (Soler-Hampejsek, Mensch et al. forthcoming). More investment is needed in addressing gender-specific barriers to acquiring, using, and retaining academic skills during and after school. 


\section{REFERENCES}

Grant, M. and J. Behrman. 2010. “Gender gaps in educational attainment in less developed countries," Population and Development Review 36(1): 71-89.

Lloyd, C.B. 2009. New Lessons: The Power of Educating Adolescent Girls. A Girls Count Report on Adolescent Girls. New York: Population Council.

Psaki, S.R., K. McCarthy, and B.S. Mensch. 2018. "Measuring gender equality in education: Lessons from 43 countries," Population and Development Review 44(1): Forthcoming.

Soler-Hampejsek, E., B.S. Mensch, S.R. Psaki, M.J. Grant, C.A. Kelly, and P.C. Hewett. "Reading and numeracy skills after school leaving in southern Malawi: A longitudinal analysis," International Journal of Educational Development. Forthcoming.

Study Group on Measuring Learning Outcomes. 2013. Schooling Is Not Education! Using Assessment to Change the Politics of Non-Learning. CGD Report. Washington, DC: Center for Global Development. www.cgdev.org/publication/schooling-is-not-education.

UNESCO. 2016a. Gender Review: Creating Sustainable Futures for All. Global Education Monitoring Report. Paris.

UNESCO. 2016b. Education for People and Planet: Creating Sustainable Futures for All. Global Education Monitoring Report. Paris. 

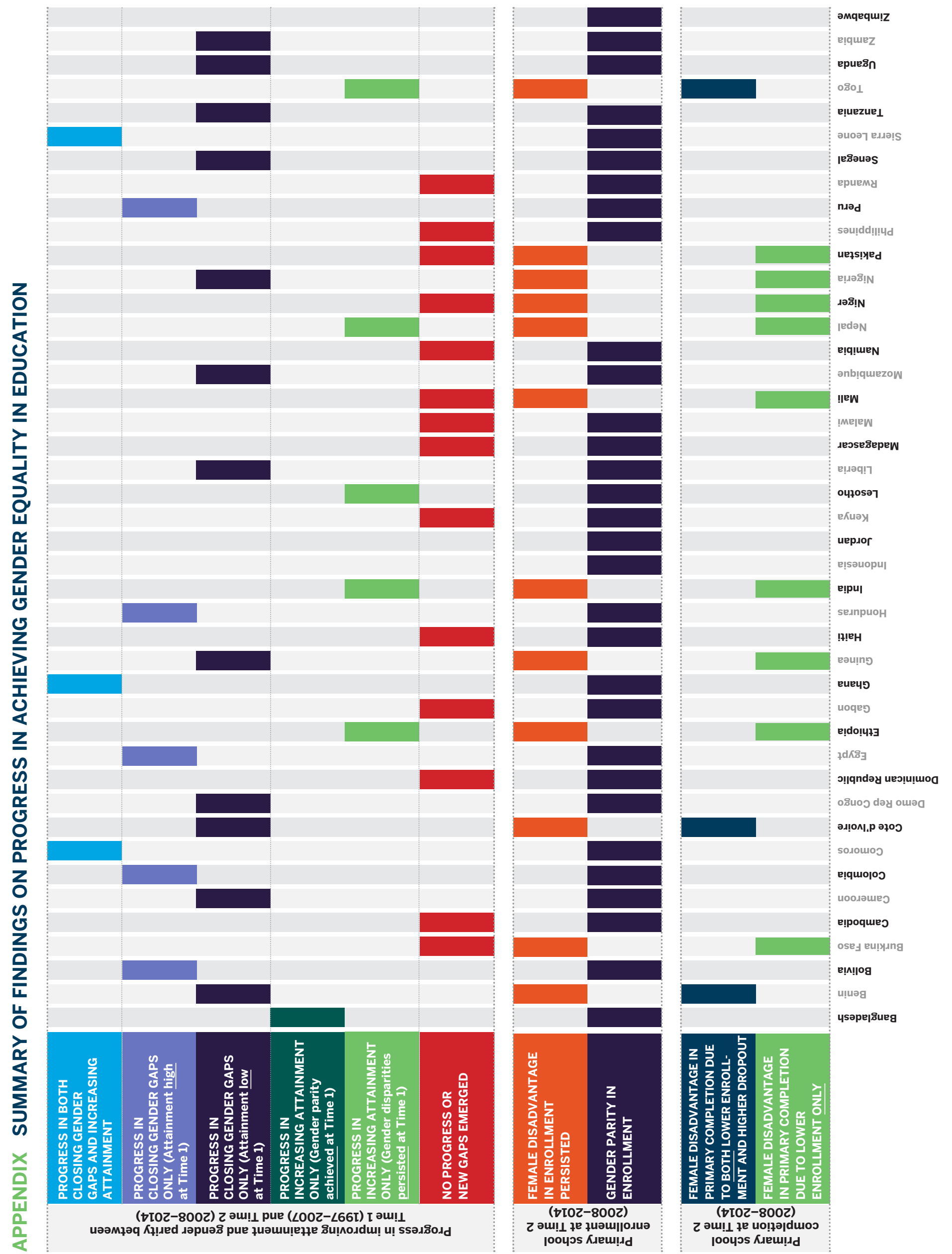